\title{
3 Research Square

\section{An Investigation Into the Presentation of Social Identity in Summit Series With a Discourse Analysis Perspective}

\section{Fatemeh Esmaeeli}

Shiraz University

\section{S.A. Razmjoo ( $\nabla$ arazmjoo@rose.shirazu.ac.ir)}

Shiraz University

\section{Mohammadreza Valizadeh}

Cappadocia University Mustafapaşa Campus: Kapadokya Universitesi https://orcid.org/0000-00024312-9731

\section{Original article}

Keywords: Identity, semiosis, identity-as-shared perceptions, identity-as-institutionalized claim, Social Actor(s), Social Action, sociocultural

Posted Date: May 5th, 2021

DOI: https://doi.org/10.21203/rs.3.rs-449876/v1

License: (c) (i) This work is licensed under a Creative Commons Attribution 4.0 International License. Read Full License 


\section{Abstract}

This study was an attempt to determine how social identity is represented in terms of social actors, social actions, and discourse practices. Following a discourse analysis perspective, Summit Series were explored in terms of five variables, namely, social actor representation, social action representation, modality, intertextuality, and idiomatic/metaphoric expressions. After enumerating and tabulating different variables and categories, the data were analyzed. The study revealed the passivation and subjection social actors as being dominant for females and the beneficialization social actors for males. Furthermore, the dominant social actions were found to be cognitive and affective reaction rather than material or semiotic actions. Hence, it was found that the examined textbook is mixed-genre with its focus on the culture of the western countries in which the ethnic groups were either marginalized or manifested as being weird. Likewise, it was revealed that there is more involvement in serious matters for men and trivial, passionate and entertaining matters for females. In fact, the textbook is following the dominant trend in which identity is represented elaborately in a specific way by manipulating various semiotic variables among which social actors, social actions, modality, intertextuality, metaphoric expressions in a particular sociocultural setting and mixed-genre presentation are worth emphasizing.

\section{Introduction}

Identity refers to a notion introduced by Bruner (1996) and indicates "the traits and characteristics, social relations, roles, and social group memberships that define who one is" (Oyserman, Elmore, \& Smith, 2012, p. 69). Following Bruner's perspective, Takaya (2008) argues about three levels of learning in the educational contexts, i.e. content learning (knowledge \& skill), other's understanding and selfunderstanding. Takaya (2008) adds that the current educational contexts have considered only the first level of learning which means research on the other two levels is missing. Considering the tenets of sociocultural theory as the recent reactions to the teaching language as a second or foreign language (ESL/EFL) clarifies that the main objective of any educational program including language teaching is development and self-regulation or self-learning (e.g. Lantolf \& Poehner, 2008).

Meanwhile, the notion of identity and identity development is at the center of any educational setting wherein the education demands the interaction between individual and culture - what is resulted into identity (Takaya, 2008). Bruner's conception of identity was mainly influenced by Vygotsky's argument about the centrality of culture in human's mental development (Takaya, 2008). Hence, education plays a crucial role in shaping and constructing individual's identities among which stoical and collective dimension are crucial. For identity, there are different directions and for this study the discourse perspective is considered wherein identity is regarded as a complex concept which needs to be explored through considering socio-cultural setting (Scollon, 1997).

Likewise, the main instruments utilized in any educational setting are textbooks among which English language textbooks are the locus of identity presentation which (un)consciously may result into identity construction. Language institutes enjoy their own professional contribution to the identity development 
among EFL/ESL students by following institutionalized and professional mediums for which textbooks play a central role. The importance of textbooks is in such a way that Skleton (1976) calls it as the "hidden curriculum" through which other concepts beside the content one are transmitted to the students. Ochs (1993, p. 287) also understood "linguistic constructions at all levels of grammar and discourse as the crucial indicators of identity especially its social dimension" which he considers as "rarely grammaticalized or explicitly encoded among different languages".

Following Hyland (2011, p. 10), identity demands "identification with some community, taking on and shaping its discourses, behaviors, values and practices to construct a self both distinct from and similar to those of its members". Hence, for Hyland (2011, p. 10), identity is a social and collective notion which is constructed through "link(ing) to situations, to relationships, and to the rhetorical positions we adopt in our routine interactions with others". Textbooks, according to sociocultural theory, are one type of mediation through which the EFL/ESL students are interacting with. It means that textbooks are the locus of identity presentation, manipulation and formation. Hence, identity, as Hyland (2011) mentions, is symbolized in language which demands that any mode of language-written or spoken-is the portrayal of identity.

Teaching a language cannot be conducted in vacuum. In other words, we need to consider a number of variables among which teachers, students and textbooks are worth mentioning. It should be noted that any language is highly connected to a particular culture and when we talk about bilingual or trilingual speakers we are talking about individuals who mediate between at least two cultures. Such an issue is highly important in the contexts wherein English is taught and is considered as a foreign language. In this regard, Sercu $(2005$, p. 1) argues that "bringing a foreign language to the classroom means connecting learners to a world culturally different from their own". Sercu $(2005$, p. vii) adds that "one of the greatest pedagogical challenges consists in integrating (language and culture) so that students get a sense of their interconnectedness". It is important to realize that learning a second or foreign language demands learning a new identity which is the cornerstone of any skill, knowledge or experience that the individuals get. Here, textbooks are a sign-based mediation wherein identity manifests itself and may result into quantitative and qualitative transformation in the learners.

Considering the aforementioned issues, the study endeavors to follow two main objectives. First to determine how social identity is represented in the Summit series in terms of gender, and second to show how the different social actors are involved in the discursive practices in the textbooks to portray gender. For the purpose of the present study, identity was explored in terms of social actor representation, processes and evaluation, modality, intertextuality, as well as metaphoric and idiomatic expressions. In meeting the objectives of the study three questions were addressed:

1. How is gender depicted in the Summit series in terms of social roles, processes and evaluation?

2. How is gender presented in the Summit Series in terms of modality, intertextuality and metaphoric expressions?

3. Which ideological practices are followed in the way the gender identity is portrayed? 


\section{Review Of Literature}

Considering the review of literature illustrates that the studies on the concept of identity can be divided into two main categories of discourse-based studies and non-discourse based studies each with their own sub-categories. The non-discourse-based studies which have been dominated in the field of EFL/ESL can be conducted by the emphasis on its relations with language achievement or performance (e.g. Razmjoo, 2012; Razmjoo \& Neissi, 2010); or identity construction in class interaction (e.g. Okada, 2015; Durnate, 2011; Dowling, 2011).

The discourse-based studies, on the other hand, enjoy more diversity and approaches which can be conducted on the media especially TV-related programs (e.g. Dash, Patnaike, \& Suar, 2016), Textbooks (e.g. Davari \& Moini, 2016; Motteram, 2016; Jannati, 2015; Alimorad, 2014; Khajavi and Abbasian, 2011), or corpus-based (McDonald \& Woodward-Kron, 2016).

The studies in which personal identity construction is investigated deal with a number of variables such as micro-discursive construction of pronoun use (e.g. Bamberg, De Fina, \& Schiffrin, 2011; Hamilton, 1998; 1996; Norris, 2008), Context-mediated activity (e.g. Durante, 2011), or metaphor and symbolism (e.g. Dowling, 2011).

The second group of discourse-based studies on identity deals with the social and historical side of identity in which several variables may be targeted such as National identity construction which is done through text analysis, narrative and interview analysis (e.g. De Cillia, Reisigl, \& Wodak, 1999), media analysis (e.g. Dash, Patnaik, \& Suar, 2016; McDonald and Woodward-Kron, 2016), and gender studies (e.g. Nilsen, 1977; Hartman \& Judd, 1978; Hellinger, 1980; O'Barr \& Atkins, 1980; Porreca, 1984; Guy et al., 1986; Holmes, 1986; Cameron \& Coates, 1988; Eckert, 1989; Peterson \& Kroner, 1992; Carroll \& Cowlitz,1994; Macaulay \& Brice, 1997;Chung, 2000; Aliakbarian, 2002; Bell et al., 2006; Stockdale, 2006; Brockway, 2007; Mineshima, 2008; Camase, 2009; Esmaili \& Amerian, 2014; Amerian \& Esmaili, 2015).

The non-discourse-based studies, on the other hand, are mainly survey-type using questionnaires to explore the relationships of identity with language achievement or performance (e.g. Razmjoo, 2012; Razmjoo \& Neissi, 2010); or identity construction in class interaction (e.g. Okada, 2015; Durnate, 2011; Dowling, 2011).

It should be noted that the non-discourse-based studies were criticized due to the fact that identity was regarded as a fixed trait not affected by the internal or external factors. Furthermore, the non-discourse based studies view identity as a final product which can be explored independent of the situational factors and has been limited to the survey design and correlational studies.

The discourse-based studies, on the other hand, is not limited to the survey and correlational studies and can be conducted on the media especially TV-related programs (e.g. Dash, Patnaike, \& Suar, 2016), Textbooks (e.g. Davari \& Moini, 2016; Motteram, 2016; Jannati, 2015; Alimorad, 2014; Khajavi \& Abbasian, 2011), or even it may be corpus-based study which provides more dependable results 
(McDonald \& Woodward-Kron, 2016). Such studies, in effect, consider identity as a dynamic trait which is situation-dependent.

One of the fields in which identity studies have attracted the attention of many researchers is genders studies in relation to the ELT textbooks which have been conducted especially through the tenets of critical discourse analysis (e.g. Alimorad, 2014; Esmaili \& Amerian, 2014; Amerian \& Esmaili, 2015; Davari \& Moini, 2016; Sarani \& Kord, 2018).

However, the studies done have paved the way for the subsequent researchers but the above mentioned studies had to consider one variable at a time. As an illustration, Sarani and Kord, (2018) investigated Touchstone series in terms of social actor representation related to gender using Van Leeuwen's (2008) and Kress and Van Leeuwen's (2006) frameworks. It seems that we need to consider several dimensions of gender identity in order to provide more dependable results. To this end, instead to solely investigate social actors related to gender like Alimorad (2014) or Sarani and Kord (2018), we endeavored to integrate the tenets of critical discourse analysis which are highly illuminative and insightful with Van Leeuwen's (2008) insightful framework to be able to explore the textbook's materials in terms of gender identities using several dimensions.

Considering the discourse-based studies indicates that these studies have explored the concept of identity through examining one of these factors: social actors' representation, mode and transitivity, intertextuality, or lexico-grammatical choices as metaphoric expressions. Hence, none of these studies tried to investigate the concept of identity through considering different factors in a more generalized and comprehensive model.

Norris $(2008$, p. 134) reminds that "identity is not formed in cohesive wholes but as situationally grounded and co-constructed identity elements". In other words, identity elements are attributed to social actors and their related issues such as social actions, modality, intertextuality or metaphoric expressions. Likewise, considering identity in terms of only one element such as pronouns, social, or sociocultural setting or genre cannot provide a complete and real picture of the process of identity representation which, according to Norris (2008), needs to be approached in order to provide a more comprehensive picture.

\section{Methodology}

In this section, the details regarding the methodology based on which this study was conducted is presented.

\subsection{Design of the study}

This study is a content analysis which follows a qualitative research design that according to Ary, Jacobs, Sorensen and Walker (2014, p. 488)) "may be done in a quantitative research framework with 
variables that are specified a priori and numbers that are generated to enable the researcher to draw conclusions".

\subsection{Materials}

Having selected the Summit series due to the fact that many Iranian EFL learners have to study it in order to get diploma in English as a foreign language, the series was investigated in terms of identity. Summit series refers to a two-level advanced course which was designed and developed by Joan Saslow and Allen Ascher (2012) and has composed of five main sections of model conversations, discussion builders, vocabulary syllabus, writing sections, and grammar booster. Hence, each volume of the series has composed of 10 units each with 4 lessons-each with two main sections of two-page multiple skills lesson at the beginning of each lesson followed by Communication activities to trace the progress of the students.

\subsection{Sampling Method}

The study has utilized purposive sampling through which Summit Series were selected as the source for gathering data on the basis that the series are being taught to many Iranian EFL learners after passing the Top Notch series in almost all language institutes around Iran. In fact, the series are presented to Iranian EFL students in terms of Summit $1 A$, Summit $1 B$, Summit $2 A$, and Summit $2 B$, out of which Summit $1 A$ was selected randomly to be explored. Likewise, the four sections of Sound Bites, Grammar Snapshot, Conversation Snapshot and Reading were analyzed in terms of the components of identity, i.e. Social Roles' Presentations, Social Actions, Intertextuality, Modality, and Socio-cultural Setting.

\subsection{Model of Analysis}

In analyzing the data, a discourse analysis model was designed which has comprised of several factors, i.e. social actor representation and related social actions and processes, modality, intertextuality, metaphoric expressions, genre and sociocultural context. It is worth mentioning that the model was adopted based on the tenets of discourse analysis. The presented model characterizes the complex nature of identity, which according to sociocultural theory is a changing and complex phenomenon that cannot be explored through a variable in a time (Enyedy, Goldberg, \& Welsh, 2006). Henceforth, the exploration of identity cannot be done through the linear and formal approaches followed by many survey-based research studies in which mainly one variable is being considered. Having considered such issues, the researcher resorted to an interdisciplinary model incorporated social actors and actions, intertextuality, idiomatic and metaphoric expressions, and genres situated in a particular sociocultural context. In other words, such a model is capable of analyzing different dimensions of the concept identity at a time.

The presented model incorporates micro- and macro-dynamics related to identity. To put it in another way, identity is manifested by different social actors through a number of social actions in which they engage (Bokszanski, 1995). In fact, different social actors may manifest themselves differently through the 
idiomatic and metaphoric expressions they use. It is not the end of the story because the interactions between different features of the language result into a number of discourses based on the purposes, approaches, social actors and actions, and contexts (Li, 2009).

Here, the role played by genre should not be ignored as genre, discourse and style reshape and reconstruct discourse in social actors (Fairlough, 2003). Finally, the whole picture is being situated in a sociocultural context without which talking about identity does not seem to be satisfactory. Hence, the identity formed by different social actors through manifesting diverse social actions and using a vast number of idiomatic and metaphoric expressions is contingent upon context, culture, lived experiences, and individual choices for which genre and intertextuality are playing their roles (Lamb, 2005; Enyedy, Goldberg, \& Welsh, 2006; Damigella, \& Licciardello, 2014).

To this end, social actor representation and related social actions and processes were analyzed resorting to van Leeuwen's (2008) model, modality through Halliday and Matthiessen (2004), intertextuality through Fairclough (2003). As it was explicated, integrating different factors from different models was done in order to have more dependable and comprehensive findings in terms of identity representation in the selected textbook. Table 1 illustrates the model.

Table 1: Model of Analysis 


\begin{tabular}{|c|c|}
\hline Factors & Classification \\
\hline \multirow{9}{*}{$\begin{array}{l}\text { Social Actor Representation } \\
\text { (van Leeuwen, 2008) }\end{array}$} & - $\quad$ Activation vs. Passivation \\
\hline & Generalization vs. Specification \\
\hline & Visualization vs. Assimilation \\
\hline & Association vs. Disassociation \\
\hline & Indetermination vs. Differentiation \\
\hline & Nomination vs. Categorization \\
\hline & Functionalization vs. Identification \\
\hline & Personalization vs. Impersonalization \\
\hline & Overdetermination vs. Symbolization \\
\hline \multirow{4}{*}{$\begin{array}{l}\text { Social Actions \& Processes } \\
\text { (van Leeuwen, 2008) }\end{array}$} & $\begin{array}{l}\text { Activation vs. Deactivation (Objectivation vs. } \\
\text { Descriptivization) }\end{array}$ \\
\hline & $\begin{array}{l}\text { Agentialization vs. Deagentialization (Eventuation, } \\
\text { Existentialization, Naturalization }\end{array}$ \\
\hline & $\begin{array}{l}\text { Abstraction (Generalization, Distillation) vs. } \\
\text { Concretization }\end{array}$ \\
\hline & $\begin{array}{l}\text { Single determination vs. Overdetermination } \\
\text { (Symbolization, Inversion) }\end{array}$ \\
\hline \multicolumn{2}{|l|}{ Modality (Halliday, 2004) } \\
\hline \multirow[t]{4}{*}{ Intertextuality (Fairclough, 2003) } & direct reporting \\
\hline & indirect reporting \\
\hline & free indirect reporting \\
\hline & narrative reporting of Speech act \\
\hline \multicolumn{2}{|l|}{$\begin{array}{l}\text { Idiomatic \& Metaphoric } \\
\text { Expressions (Lukeš, 2005) }\end{array}$} \\
\hline \multicolumn{2}{|l|}{ Genre } \\
\hline Sociocultural Context & \\
\hline
\end{tabular}

\subsection{Procedures}

The first step for the study is collecting data. To this end, different sections of Sound Bites, Grammar Snapshots, Conversation Snapshots, and Readings were coded using different colors and numbers based on different variables to be extracted according to the model presented in the previous section. Then, the 
data were tabulated in terms of different categories and percentages followed by some examples. After that, the extracted data were presented logically in terms of different dimensions of Identity in such a way to illustrate social identity wherein the relation between different social actors, social actions, modality, intertextuality, general and sociocultural setting were clarified.

\section{Results And Discussion}

In analyzing the data, the percentages of the idiomatic expressions, modality utilizations, social roles, intertextuality uses, and activities were numerated in relation to the social actors and actions which were divided into two groups of male and female due to the fact that gender manipulation was dominant in the textbook.

Table 2: Gender representation in terms of related issues to identity representation

\begin{tabular}{|lllllll|}
\hline & $\begin{array}{l}\text { Metaphoric } \\
\text { Expressions (\%) }\end{array}$ & $\begin{array}{l}\text { Social } \\
\text { actors (\%) }\end{array}$ & $\begin{array}{l}\text { Social } \\
\text { roles (\%) }\end{array}$ & $\begin{array}{l}\text { Modality } \\
(\%)\end{array}$ & $\begin{array}{l}\text { Intertextuality } \\
(\%)\end{array}$ & $\begin{array}{l}\text { Total } \\
(\%)\end{array}$ \\
\hline Male & 69.2 & 65.3 & 62.5 & 67.5 & 66.6 & 66.2 \\
\hline Female & 30.8 & 34.7 & 37.5 & 32.5 & 33.4 & 33.8 \\
\hline Total & 17 & 56 & 7 & 16 & $9(4 \%)$ & 100 \\
\hline
\end{tabular}

Considering the results in Table 2 illustrates that male characters are depicted in higher proportion comparing their female counterparts. In fact, the total presentation of males was $66.2 \%$ and the presentation of females was $33.8 \%$. It is important to realize that males were mainly depicted in relation to social and business activities such as company picnic whereas the females were showed in relation to entertaining activities such as outdoor wedding or dinner party. The most compelling evidence may be attained in unit three which is around the topic of beauty in which mainly women are depicted in relation to beauty such as skin lightening, tanning, facial piercing or makeup and nails. In unit three also some evidence can be observed in which males are depicted especially in relation to hairstyles, for instance, buzz cut, hair transplant, braids, goatee, etc. Likewise, the males are overrepresented in this textbook apart from the higher social roles attributed to them. As an illustration, ethnicity was also manipulated in the textbook in which the weird and strange beauty-related activities are mentioned semiotically, for example, geisha by Japanese women, gold bands by Myanmar woman, extravagant wigs by Europeans, or face decoration by Maori men.

Another key point is related to intertextuality utilization wherein direct reporting are utilized but humane and virtuous ones were reported about the males (e.g. I respect generosity in people. I don't look at it as philanthropy. I see it as an investment in the community. I am not a professional philanthropist) and pedantic one about females which is apparently extracted from a song (e.g. Am I not pretty enough? Why do you see right through me? Just like models or movie stars). As can be seen in the Table, the social 
roles (e.g. activation, passivation, generalization, specification, etc.) were mainly depicted to be performed by males about $62.5 \%$ comparing their female counterparts whose contribution is less than $40 \%$. As an illustration, in unit one, there is a conversation between Leo and Lora talking about a new virus and in this conversation the activation role is given to Leo who is a male character, more knowledgeable and provide more determined ideas such as you're just a sitting duck or better safe than sorry when he is talking about the spread of the new virus known as Chikungunya whereas Lora here admitted a more passive role and tries to portray the situation as not being serious by saying it's still pretty rare or you've got to role with the punches which she means she have to participate in the company dinner. Here, male characters can be considered as more engaging in different social roles as the above Table illustrates.

Furthermore, modality utilization was also higher by males comparing females which may due to their higher presentation which also is in a wider range comparing the females. Likewise, the modality utilization for males denotes a greater level of certainty such as definitely, mostly, fortunately, totally, really, etc. while, the female' tendency was toward the more moderate modals such as actually, pretty, frankly, can't, really, maybe, etc.

The textbook also provides different metaphoric and idiomatic expressions for the both genders however the range and number of the expressions seem to be more diverse for males comparing the females. As an illustration, the men's tendency was towards utilizing the expressions such as bugs me, gets on my nerves, stay at your own tows, kick myself, etc. Whereas, the women showed the tendency towards utilizing the expressions such as burning the candle at both ends, gets on my nerves, within my means, hello (for showing that somebody has said something stupid), etc.

Table 3 illustrates the social actors in terms of the first categorization, namely, activation vs. passivation (subjection \& beneficialization). Such results denote that male characters' representation is outnumbered comparing females and it is not limited solely to overrepresentation since male characters are more engaging in activation, subjections and beneficialization. It may infer that there are some traces of gender biases. Accordingly, the allocation of social actor roles to males is higher which has been done through a number of means such as pronouns, clauses or idiomatic expressions attributed to males such as $\mathrm{He}$ founded and denoted all profits to charity or it really bugs me off.

Table 3: Role allocation to each gender (activation vs. passivation)

\begin{tabular}{|llll|}
\hline Gender & Activation (\%) & Passivation & \\
\cline { 3 - 4 } & & Subjection (\%) & Beneficialization (\%) \\
\hline Male & 55 & 39 & 45 \\
\hline Female & 45 & 9 & 7 \\
\hline Total & 100 & 48 & 52 \\
\hline
\end{tabular}


Table 4, on the other hand, shows the actors roles distributions in terms of personalization and Impersonalization. According to the Table, $39 \%$ of the social actors were personalized by male characters whereas $31 \%$ of them were not impersonalized and were solely related to female characters. Furthermore, $30 \%$ of the represented social actors were personalized by female characters. It should be noted that the male characters were portrayed solely by personalization for example through their names or pronouns like $\mathrm{Leo}$ or $\mathrm{He}$, but in portraying female characters, an almost equal percentage is utilized for persona representation, such as the nouns or pronouns of teenagers, people, others, you, or we.

Table 4: Social Actor allocation to each gender (personalization vs. Impersonalization)

\begin{tabular}{|c|c|c|}
\hline Gender & Personalization & Impersonalization \\
\hline Male & 39 & 0 \\
\hline Female & 30 & 31 \\
\hline Total & 69 & 31 \\
\hline
\end{tabular}

A key point regarding the results was that the Impersonalization social actors were mainly reproduced in terms of collectivization through a mass noun or a noun denoting a group of people such as a number of, many, several, more, a little over half of all, one third of, every, a great deal of, some, a lot of, less, each, a few, a few, a majority of, etc.

Table 5: Social Action allocation to each gender

\begin{tabular}{|lllll|}
\hline Gender & Action (\%) & \multicolumn{3}{c|}{ Reaction (\%) } \\
\hline Material (\%) & Semiotic (\%) & Cognitive (\%) & Affective (\%) \\
\hline Female & 12 & 23 & 29 & 29 \\
\hline Total & 31 & 19 & 32 & 37 \\
\hline
\end{tabular}

Considering the results in Table 5 clarifies that the reaction type of social actions is dominant in the textbook. In fact, clauses or sentences are put around the reaction processes, for instance, gets to me, ticks me off, bugs me,gets on my nerves, or I think as a few among others. As an illustration consider the following examples of the action processes:

Clothing should express your individuality. I don't want to dress the same as everyone else. I prefer to stand out in a crowd.

The above example not only illustrates cognitive mental processes which are also ideological but also affective reactions which are highly related to feelings, wishes, and hopes of the female cheaters. Here, 
some traces of stereotyping can be observed in which being concerned with the superficial issues such as clothing is represented.

The textbook may be considered as a mixed-genre document portraying different social actors along with their social actions, using modality, intertextuality and metaphoric as well as idiomatic expressions in a particular sociocultural context which mainly is depicting the western culture. Analyzing the textbook selected out of the Summit series showed that the ethnicity was rarely presented and the underrepresentation and reconstruction was only related to the weird and unusual cultural backgrounds such as the definition of beauty by Asian, African and southwest Europeans such as geisha by Japanese women, gold bands by Myanmar woman, extravagant wigs by Europeans, or face decoration by Maori men.

Accordingly, the textbook was designed in such a way to emphasize the western and American culture wherein the higher social roles and actions were attributed to non-ethnic groups and especially to men. Put in another way, women were depicted in more passive and marginalized ways and in some cases, the female characters are portrayed in relation to affective reactions reflecting females' feelings, wishes, hopes and needs associated with the more superficial issues like beauty, shopping, etc.

In the same way, the dominant social actors were passivation and subjection for females who were treated as the object and beneficialization for males who were getting benefits from an action. Likewise, both genders were highly depicted as personalized social actors which denotes them as human beings through personal, possessive or even nominalization processes.

Furthermore, social actions were mainly in terms of cognitive and affective reaction rather than material or semiotic actions. The differences between the two genders in using idiomatic expressions, intertextuality realization and even modality shed light on gender identity representation.

By all means, the textbook seems to be focused on fiction and non-fiction genres especially the biography centered on the life of people from the USA or western countries in which the ethnic groups are marginalized and underrepresented. Depiction of the two genders also indicated more involvement in serious matters for men while the women are being involved in their personal and entertaining matters. Almost all interactions were between opposite genders who are either talking about perspectives, musical moods, money matters, beauty and community which in one way or another was denoting capitalism or consumerism, for instance Newman Salad dressing.

In conducting the present study three questions were raised in order to explore gender identity representation in the ELT textbooks. To this end, social actors and actions along with the modality, intertextuality and metaphoric expressions were examined in terms of gender representation. The present study as many other studies showed that male characters are overrepresented (e.g. Nilsen, 1977; Hartman \& Judd, 1978; Hellinger, 1980; O'Barr \& Atkins, 1980; Porreca, 1984; Guy et al., 1986; Holmes, 1986; Cameron \& Coates. 1988; Eckert, 1989; Peterson \& Kroner, 1992; Carroll \& Cowlitz,1994; Macaulay \& 
Brice, 1994 \&1997; Chung, 2000; Aliakbarian, 2002; Bell et al., 2006; Stockdale, 2006; Brockway, 2007; Mineshima, 2008; Camase 2009; Esmaili \& Amerian, 2014; Amerian \& Esmaili, 2015).

Identity is a life-long process which is shaping and influenced by different variables among which the ELT textbooks exposing to the learners cannot be ignored. It is assumed that individual's identity and actions form a praxis, in which individual's identity is formed by different variables including society, culture, the significant others, social relationships, textbooks, educational settings, etc. Meanwhile, it affects and shapes our social relationships, culture, society, favorite books, etc. What is missing here is that we need to consider the textbooks presented to the learners by which their culture, identity, actions, reactions, attitudes may be affected. Such an argument is what is called hidden curriculum by Skleton (1976).

Considering the recent theories on identity, i.e. identity in intercultural competence (e.g. Deardorff, 2009), capitalizes the importance of identity which is the interface of the three main components of intercultural competence, i.e. knowledge, skills/behavior, and attitudes/traits. Such a concept is also fundamental in textbooks in general and ELT textbooks in particular. The importance of identity in the ELT textbooks can also be justified by considering the representation of national, cultural, ethnolinguistic, racial, and religious identity.

Two concepts of "identity inclusivity" and "identity security" can be referred to in discussing the findings of the present study. Whereas, identity inclusivity demonstrates the individuals' tendency for categorizing themselves or others as in-group or out-group members (Deardorff, 2009). Identity security illustrates "the degree to which individuals feel secure in their identity" (Deardorff, 2009, p. 57). Identity security, in effect, may equip the learners with the required strategies in order to "engage in associative behaviors and activities involving culturally dissimilar others" (Deardorff, 2009, p. 57). Accordingly, overrepresentation of a gender may target identity inclusivity in which the overrepresented gender, male characters in the present study, is regarded as in-group members and the underrepresented gender, here females, is outgroup members.

Another equally important issue is related to identity security which can be affected by the gender representation which exists in the textbooks by which a gender may feel unconformable to engage in the culturally dissimilar others when nationality, ethnicity, social actors and actions are being divided through overrepresentation or underrepresentation. In this regard, Deardorff (2009) argues that the distinction between in-groups (us) and out-groups (them) results to centralizing differences or decentralizing similarities.

When we have overrepresentation, we may infer that the gender overrepresented is a member of conventional social category by which we are following universalization processes. On the other hand, the underrepresented gender is a singular individual and not a member of a conventional social group which is depicting individuation processes. The results of the present study also showed that gender categories-social actor, social action, modality, intertextuality, idiomatic and metaphoric expressionsare being accentuated and cognitive differentiation and particularization are represented differently. 
All in all, language textbooks including the Summit series is an enterprise which consciously is depicting identity in a specific way through manipulation of various semiotic variables among which social actors, social actions, modality, intertextuality, metaphoric expressions in a particular sociocultural setting and mixed-genre presentation are worth emphasizing. Hence, semiotic presentation-linguistic or nonlinguistic-plays a crucial role in identity representation to which many EFL/ESL learners are exposed to. The portrayals of identity either in terms of exclusion or inclusion may transmit some secondary information which unconsciously influences the identity in the mind of language learners especially the teenagers who are in the process of their identity portrays.

\section{Conclusions}

Language as a social practice is constructed by the processes of identity construction influenced by a number of factors including social actors and social actions which in turn may be affected by some variables such as intertextuality, social roles, modality, etc. Identity, in effect, is a multi-dimensional construct changing and struggling in a sociocultural setting influences and is influenced by learning a foreign or second language.

Having conducted the study, passivation and subjection social actors were found to be dominant for females and the beneficialization social actors for males. In addition, the dominant social actions were found to be cognitive and affective reactions rather than material or semiotic actions. Furthermore, the results of the study showed that the examined textbook is mixed-genre with its focus on the culture of the western countries in which the ethnic groups were either marginalized or manifested as being weird.

The findings of the study also showed more involvement in serious matters for men and trivial, passionate and entertaining matters for females. The examined textbook, in effect, is following the dominant trend in which identity is represented elaborately in a specific way by manipulating various semiotic variables among which social actors, social actions, modality, intertextuality, metaphoric expressions in a particular sociocultural setting and mixed-genre representation are worth emphasizing. Exclusion or inclusion identity representation may transmit some secondary information which unconsciously influences the identity in the mind of language learners especially the teenagers who are in the process of their identity portrays.

Among different factors, hegemony and power manipulated by the elites including EFL textbooks undertaken by enterprises under the control of western and American culture seems to influence identity among the EFL learners. This issue also reminded by Skleton (1976) through the notion of "hidden curriculum".

The role played by identity in language learning may be justified through considering the fact that it is, in effect, identity that "differentiate(s) and integrate (s) a sense of self along different social and personal dimensions such as gender, age, race, occupation, gangs, socio-economic status, ethnicity, class, nation states, or regional territory" (Bamberg, 2010, p. 1). 
Under such circumstances where some ethnic groups, or a gender, occupation, nation, etc. are underrepresented or even excluded in a sociocultural setting, in a particular genre or in respect to some social actors and actions; the identity of EFL learners may be influenced in one way or another. Similarly, the way language is presented to the learners along with its content is crucial due to the cultural, psychological and collective impacts.

\section{Pedagogical Implications}

In the light of aforementioned issues, the results of the study may have some pedagogical implication for all those who are concerned with teaching or learning language among whom teachers, teacher' trainers, curriculum developers and syllabus designers as well as learners are worth mentioning. the content of the ELT series may be supplemented by some well-designed and nativized materials means that the present series including the Summit series may be taught along with some other materials designed and developed based on learners' needs and cultural consideration. However, a conscious-raising forum in which the learners' awareness be increased seems to be effective especially through Critical reflection to enable both teachers and learners as well as teacher's trainers to become reflective practitioners by subjecting their practices-teaching or learning to ongoing assessment by which improve their performances. Hence, the results of the study may widen the horizon of understanding especially among teachers not to limit themselves to the textbooks and consider the weaknesses and influences the ELT martials have on the learners.

Hence, considering education as a political enterprise underscores the role played by EFL textbooks in an attempt to equip the learners to think critically in order to be equipped in perpetuating appropriate ways of thinking, acting and interpreting. It is important to realize that learning a second or foreign language demands learning a new identity and a new culture by which learners' skills, knowledge or experiences may be changed or even transformed. According to Whetten and Mackay (2002, p. 399), the kind of identity in relation to gender and ethnicity which may be depicted in terms of exclusion by underrepresentation can capitalize identity-as-shared perceptions as well as identity-as-institutionalized claim-by which he meant that the represented identity is in line with the hidden curriculum and the type of identity which is attempted to be perpetuated by some institution such as textbooks publishers, the kind of perceptions that such organizations try to form by excluding or underrepresenting females or other nationalities and ethnicities other than American and European.

\section{Abbreviations}

EFL: English as a Foreign Language

ELT: English Language Teaching

ESL: English as Second Language

SPSS: Statistical Pack for Social Sciences References 


\section{Declarations}

\section{Availability of data and materials:}

All data generated or analyzed during the study were included in the article in terms of the provided examples or the data presented in the tables.

Funding: No funding was available to the present study.

Competing interests: The authors declare that they have no competing interests.

Authors' contributions: The first author extracted the data. The three authors codified and analyzed the data. All authors are responsible for all parts of the paper. The author(s) read and approved the final manuscript.

\section{References}

1. Aliakbarian, M. (2002). Culture in ELT programs: An evaluation of the issues of culture in the Iranian EFL programs in high school level. Unpublished doctoral dissertation, Isfahan University, Iran.

2. Alimorad, Z. (2014). Examining identity options in native and nonnative produced textbooks taught in Iran: A critical textbook evaluation. Research in Applied Linguistics, 5(2), 95-112.

3. Amerian, M., \& Esmaili, F. (2015). Language and gender: A critical discourse analysis on gender representation in a series of international ELT textbooks. International Journal of Research Studies in Education, 4(2), 3-12.

4. Ary, D., Jacobs, L. C., Irvine, C. K. S., \& Walker, D. (2014). Introduction to research in education. Boston: Cengage Learning.

5. Bamberg, M. (2010). Identity and Narration: the living handbook of narratology. Hamburg: Hamburg University Press.

6. Bamberg, M., De Fina, A., \& Schiffrin, D. (2011). Discourse and identity construction. In Handbook of identity theory and research (pp. 177-199). New York: Springer.

7. Bell, C. M., McCarthy, P. M., \& McNamara, D. S. (2006). Variations in language use across gender: Biological versus sociological theories. In Proceedings of the Annual Meeting of the Cognitive Science Society (Vol. 28, No. 28).

8. Bokszanski, Z. (1995). Identity of the social actor and social change. Polish Sociological Review, 349-360.

9. Brockway, E. M. (2007). The portrayal of the Middle East in secondary school US textbooks (Doctoral dissertation, Bowling Green State University).

10. Camase, G. (2009). The ideological construction of a second reality: A critical analysis of a Romanian EFL textbook. Unpublished master's thesis, University of Toronto, Toronto, Canada. 
Retrieved July 14, 2010 from

https://tspace.library.utoronto.ca/bitstream/1807/18099/1/Camase_Greta_200911_MA_thesis.pdf.

11. Cameron, D., \& Coates, J. (1988). Some problems in the sociolinguistic explanation of sex differences. In J. Coates \& D. Cameron (Eds.), Women in their speech communities (pp. 13-26). London: Longman.

12. Caroll, D., \& Kowlitz, J. (1994). Using concordancing techniques to study gender stereotyping in EFL textbooks. In J. Sunderland (Ed.), Exploring gender: Questions and implications for English language education (pp. 73-82). New Jersey: Prentice Hall.

13. Chung, H. S. (2000). Women's roles and gender issues in primary school textbooks: Korea and Mexico. Santiago: University of California.

14. Damigella, D., \& Licciardello, O. (2014). Identity development processes and socio-cultural contexts: A study with second generation adolescents. Procedia-Social and Behavioral Sciences, 141, 11271133.

15. Dash, A. K., Patnaik, P., \& Suar, D. (2016). A multimodal discourse analysis of globalization and cultural identity in three Indian TV commercials. Discourse \& Communication, 10(3), 209-234.

16. Davari, S., \& Moini, M. R. (2016). The representation of social actors in Top Notch textbook series: A critical discourse analysis perspective. International Journal of Foreign Language Teaching and Research, 4(13), 69-82.

17. De Cillia, R., Reisigl, M., \& Wodak, R. (1999). The discursive construction of national identities. Discourse \& Society, 10(2), 149-173.

18. Deardorff, D. K. (Ed.). (2009). The SAGE handbook of intercultural competence. CA: Sage Publication.

19. Dowling, S. J. (2011). Constructing identity construction. Dowling, Thesis, S. J. Georgia State University, 2011. http://scholarworks.gsu.edu/art_design_theses/88.

20. Durante, M. (2011). The online construction of personal identity through trust and privacy. Information, 2(4), 594-620.

21. Eckert, P. (1989). The whole woman: Sex and gender differences in variation. Language Variations and Changes, 1(3), 245-268.

22. Enyedy, N., Goldberg, J., \& Welsh, K. M. (2006). Complex dilemmas of identity and practice. Science Education, 90(1), 68-93.

23. Esmaili, F., \& Amerian, M. (2014). Gender representation in Iranian high school English textbooks with a critical discourse analysis perspective. International Journal of Language Learning and Applied Linguistics World, 5(4), 277-289.

24. Fairclough, N. (2003). Analysing discourse: Textual analysis for social research. East Sussex: Psychology Press.

25. Guy, G., Horvath, B., Vonwiller, J., Paisley, E., \& Rogers, E. (1986). An intonational change in progress in Australian English. Language in Society, 15(1), 23-52. 
26. Halliday, M. A. K., \& Matthiessen, C. (2004). Introducing functional grammar. New York: Edward Arnold.

27. Hamilton, H. E. (1996). Intratextuality, intertextuality, and the construction of identity as patient in Alzheimer's disease. Text-Interdisciplinary Journal for the Study of Discourse, 16(1), 61-90.

28. Hamilton, H. E. (1998). Reported speech and survivor identity in on-line Bone Marrow transplantation narratives. Journal of Sociolinguistics, 2(1), 53-67.

29. Hartman, P. L., \& Judd, E. L. (1978). Sexism and TESOL materials. TESOL Quarterly, 12(4), 383-393.

30. Helinger, M. (1980). For men must work, and women must weep: Sexism in English language textbooks used in German Schools. In C. Kramerae (Ed.), The voices and words of women and men (pp. 267-274). New York: Pergamum Press.

31. Holmes, J. (1986). Functions of you know in women's and men's speech. Language in Society, 15(1), $1-22$.

32. Hyland, K. (2011). Projecting an academic identity in some reflective genres. Ibérica: Revista de La Asociación Europea de Lenguas Para Fines Específicos, (21), 9-30.

33. Jannati, S. (2015). Gender representation in EFL textbooks: A case of ILI pre-intermediate series. Journal of Applied Linguistics and Language Research, 2(3), 211-222.

34. Khajavi, Y., \& Abbasian, R. (2011). English language teaching, national identity and globalization in Iran: The case of public schools. International Journal of Humanities and Social Science, 1(10), 181186.

35. Lamb, R. (2005). Modeling the social actor. North American Association for Computational Social and Organizational Systems (NAACSOS), Notre Dame, Indiana.

36. Lantolf, J., P. \& Poehner, M., E (2008). Sociocultural theory and the teaching of second languages. London: Equinox Publishing LTD.

37. Li, J. (2009). Intertextuality and national identity: discourse of national conflicts in daily newspapers in the United States and China. Discourse \& Society, 20(1), 85-121.

38. Macaulary, M., \& Brice, C. (1997). Don't touch my projectile: Gender bias and stereotyping in syntactic examples. Language, 73(4), 798-825.

39. McDonald, D., \& Woodward-Kron, R. (2016). Member roles and identities in online support groups: Perspectives from corpus and systemic functional linguistics. Discourse \& Communication, 10(2), 157-175.

40. Mineshima, M. (2008). Gender representations in an EFL textbook. Bulletin of Niigata Institute of Technology, 13, 121-140.

41. Motteram, G. (2016). Membership, belonging, and identity in the twenty-first century. ELT Journal, 70(2), 150-159.

42. Nilsen, A. (1977). Sexism in children's books and elementary classroom materials. In Nilsen, A., Bosmajian, H., Gershuny, H. \& Stanley J. (Eds). Sexism and language. (pp. 161-179). Urbana I11ionois: National council of Teachers of English. 
43. Norris, S. (2008). Some thoughts on personal identity construction. Advances in Discourse Studies, VK Bhatia, J. Flowerdew, \& RH Jones (Eds.), 132-147.

44. O'Barr, W., \& Atkins, B. (1980). Women's language or powerless language? In S. McConnell-Ginet, R. Brocker \& N. Furman (Eds.), Women and language in literature and society (pp. 93-220). New York: Praeger.

45. Ochs, E. (1993). Constructing social identity: A language socialization perspective. Research on language and social interaction, 26(3), 287-306.

46. Okada, Y. (2015). Contrasting identities: a language teacher's practice in an English for Specific Purposes classroom. Classroom Discourse, 6(1), 73-87.

47. Oyserman, D., Elmore, K., \& Smith, G. (2012). Self, self-concept, and identity. Handbook of self and identity, 2, 69-104.

48. Peterson, S., \& Kroner, T. (1992). Gender biases in textbooks for introductory psychology and human development. Psychology of Women Quarterly, 18(4), 704-724.

49. Porreca, K. L. (1984). Sexism in current ESL textbooks. TESOL Quarterly, 18(4), 704-724.

50. Razmjoo, A. (2012). Language and identity in the Iranian context: The impact of identity aspects on EFL learners' achievement. Journal of Teaching Language Skills, 2(2), 99-121.

51. Razmjoo, S. A., \& Neissi, S. (2010). Identity processing styles and language proficiency among Persian learners of English as a foreign language. Psychological reports, 107(3), 822-832.

52. Sarani, A., \& Kord, S. (2018). A Study of the Representation of Social Actors in Touchstone Series: A Critical Discourse Analysis Perspective. Teaching English Language, 12(1), 111-133.

53. Scollon, R. (1997). Discourse identity, social identity, and confusion in intercultural communication. Intercultural Communication Studies, 6, 1-16.

54. Sercu, L. (2005). Foreign language teachers and the implementation of intercultural education: a comparative investigation of the professional self-concepts and teaching practices of Belgian teachers of English. French and German. European journal of teacher education, 28(1), 87-105.

55. Skelton, A. (1997). Studying hidden curricula: Developing a perspective in the light of postmodern insights. Curriculum studies, 5(2), 177-193.

56. Stockdale, D. A. (2006). Gender representation in an EFL textbook. Master's thesis, University of Birmingham, UK. Retrieved from http://www. cels. bham. ac. uk/resources/essays/ DAStockdaleSociolinguistics. pdf.

57. Takaya, K. (2008). Jerome Bruner's theory of education: From early Bruner to later Bruner. Interchange, 39(1), 1-19.

58. Van Leeuwen, T. (2008). New tools for critical discourse analysis. Oxford: Oxford University Press.

59. Whetten, D. A., \& Mackey, A. (2002). A social actor conception of organizational identity and its implications for the study of organizational reputation. Business \& Society, 41(4), 393-414. 